\title{
MINERAL DISTRIBUTION IN RELATION TO FRUIT DEVELOPMENT AND MONOCARPIC SENESCENCE IN ANOKA SOYBEANS ${ }^{1}$
}

\author{
Belma D. Derman, ${ }^{2}$ David C. Rupp, and Larry D. Noodén \\ Botany Department, University of Michigan, Ann Arbor 48109
}

\section{A B S T R A C T}

\begin{abstract}
The changes in distribution of several important mineral nutrients ( $\mathrm{N}, \mathrm{K}, \mathrm{Ca}, \mathrm{Mg}, \mathrm{Mn}$, and $\mathrm{Fe}$ ) were studied in relation to monocarpic senescence (measured as leaf yellowing) and fruit development in hydroponically-grown (and to a lesser extent field-grown) Anoka soybeans with particular emphasis on the leaves and seeds. Only $\mathrm{N}$ shows a clear redistribution from the leaves to the seeds as the seeds grow, and this transfer starts before visible leaf yellowing. $\mathrm{K}, \mathrm{Ca}, \mathrm{Mn}$ and $\mathrm{Fe}$ do not seem to redistribute, but $\mathrm{Mg}$ may undergo limited redistribution. Depodding prevents the drop in the amounts of minerals in attached leaves by blocking leaf shedding and/or redistribution and also creates some quantitative changes in mineral distribution. On a $\mathrm{g}$ fresh weight basis, only the $\mathrm{N}$ content of leaf blades decreases during yellowing; the $\mathrm{K}, \mathrm{Mg}, \mathrm{Ca}, \mathrm{Mn}$ and $\mathrm{Fe}$ contents do not decrease. Therefore, depletion of the latter minerals from the leaves cannot be responsible for their yellowing. Although $\mathrm{N}$ deficiency alone could cause foliar chlorosis, the monocarpic yellowing pattern is distinctly different from that induced by $\mathrm{N}$ deprivation.
\end{abstract}

THE CONTENT of at least some minerals (particularly nitrogen) appears to decrease in senescing plant organs (see Gregory, 1937; Miller, 1938; Williams, 1955; Howell, 1960; Ohlrogge, 1963; Hanway and Weber, 1971; deMooy, Pesek, and Spaldon, 1973; Kollman et al., 1974; Noodén and Leopold, 1978). Often, this loss from senescing organs is counterbalanced by a corresponding increase in storage tissues of developing fruit and therefore seems to represent withdrawal from the senescing organs. In general, these studies are concerned with the relationship of mineral distribution to fruit development rather than with senescence. From these data, one cannot determine how the start of changes in mineral distribution relates to the start of senescence or how the rates of these two processes are related. Furthermore, the apparent decrease in mineral content may in many cases be the result of shedding of the senescing organs rather than redistribution. This apparent redistribution of minerals from the vegetative parts to the developing fruit of monocarpic plants has given rise to the suggestion that the fruit kill the plants by depleting their vegetative parts (especially the leaves) of needed minerals (see Noodén and Leopold, 1978). This theory is supported by the observations that removal of the flowers or young fruit (the apparent sinks) can prevent or at least delay senescence in

\footnotetext{
1 Received for publication 11 May 1977; revision accepted 18 July 1977.

Supported in part by research grant number 416-15-79 from the USDA Cooperative State Research Service under P.L. 89-106.

${ }^{2}$ Present address: Department of General Botany, University of Istanbul, Süleymaniye, Istanbul, Turkey.
}

many monocarpic plants including soybeans (Leopold, Niedergang-Kamien, and Janick, 1959; Lindoo and Noodén, 1976; Noodén and Leopold, 1978). Furthermore, any of several mineral deficiencies can produce leaf yellowing (Sprague, 1964), though no single deficiency syndrome precisely matches the yellowing patterns which develop during monocarpic senescence of soybeans. Because it is essential to have a clear picture of mineral withdrawal or redistribution in relation to senescence, we have analyzed the distribution of certain essential minerals in relation to the time course of fruit development and senescence of soybeans and also the effect of depodding (which prevents monocarpic senescence in soybeans) on mineral distribution as part of a study on the physiology of monocarpic senescence in soybeans.

Materials AND METHODS-Plant culture and measurement of development-Soybean (Glycine $\max (\mathrm{L}$.) Merrill cv. Anoka) seeds were sown in vermiculite, and when the primary leaves had unfolded (at approximately 10 days), the plants were transferred to plastic freezer containers with about 1 liter of full strength, modified Hoagland's solution plus iron EDTA (Arnon and Hoagland, 1940). Two plants were placed in opposite corners of each container. The level of the solution was restored daily with distilled water, and every 14 days, the solution was replaced with fresh Hoagland's solution. Solutions were aerated at a rate of $30 \mathrm{ml} / \mathrm{min}$ with air previously bubbled through water. The plants grew vigorously under these conditions with no sign of min- 
eral deficiency (yellowing or slowing of growth rate) before fresh mineral solution was added.

For the first 30 days, the plants were cultured at $26 \mathrm{C}$ in a growth chamber with continuous incandescent light and $10 \mathrm{hr}$ fluorescent light each day (intensities given in Lindoo and Noodén, 1976). After 30 days, the light regime was changed to a short-day photoperiod of $10 \mathrm{hr}$ light at $26 \mathrm{C}$ and $14 \mathrm{hr}$ darkness at $19 \mathrm{C}$.

Senescence (leaf yellowing) and fruit maturity index (FMI) were scored using the method of Lindoo and Noodén (1976). Fruit on depodded plants were removed at stage 2 starting at FMI 1.5 (short day 32 ) and every $3-4$ days thereafter.

Although hydroponic plants grown in environmental control chambers have many advantages (better control, ease of collection of roots or fallen leaves), they differ considerably from field-grown plants (the former being taller, having thinner stems and leaves and lacking root nodules). Thus, it seemed valuable to do some checks on field-grown plants to see if the same general picture would hold true, so plants were also grown outdoors at The University of Michigan's Matthaei Botanical Gardens by using standard agricultural equipment. Seeds inoculated with Rhizobium japonicum (soybean inoculant, Rudy Patrick Co., Inoculant Labs, Princeton, Ill.) were drilled about 2 in. deep in rows 36 in. apart during the last week of May in soil which had previously been plowed, disked and fertilized (10-6-4, about $200 \mathrm{lb}$ per acre). The soil was cultivated twice, and the plants were irrigated as needed. Several rows were depodded twice weekly starting when the fruit maturity index was about 1.5 and thereafter as the fruit reached stage 2 .

Plant harvest and acid digestion-Podded and depodded plants were harvested at about 1 PM every 4 days starting about FMI 1.3, about August 1 for field-grown plants or short day 32 for hydroponic plants. The harvested plants were separated into stems, petioles, leaf blades, carpels, and seeds (also roots for hydroponic plants), and their fresh and dry weights were determined as previously described (Lindoo and Noodén, 1976). For hydroponic plants, fallen blades and petioles were also collected and measured separately. The pods removed from the depodded plants were frozen and stored at $-13 \mathrm{C}$ until analyzed. Field-grown plants were likewise kept at $-13 \mathrm{C}$ from harvest until they were used.

Dried plant material was digested in concentrated $\mathrm{H}_{2} \mathrm{SO}_{4}$ with $0.2 \%(\mathrm{w} / \mathrm{v}) \mathrm{Na}_{2} \mathrm{SeO}_{4}$ and $0.1 \%$ (w/v) $\mathrm{CuSO}_{4} \cdot 5 \mathrm{H}_{2} \mathrm{O}$ as catalysts (Dawson et al., 1969). Approximately $0.01 \mathrm{~g}$ of dry plant material was added to $1.0 \mathrm{ml}$ of the digest solution which was then heated in a sand bath at $280 \mathrm{C}$ until 8-12 $\mathrm{hr}$ after the solution became colorless (approxi- mately $48 \mathrm{hr}$ ). The digestion solution was then diluted to $10.0 \mathrm{ml}$ with $\mathrm{H}_{2} \mathrm{O}$. Six digestions were made for each plant organ at every harvest date.

Nitrogen determination-The nitrogen content in the digested plant samples was determined by the following procedure modified from Middleton (1960). This is the classical Kjeldahl digestion with a catalyst (Humphries, 1956), except that the nitrogen was determined in the digest with Nessler's reagent. To $1.0 \mathrm{ml}$ of diluted digest solution, $4.0 \mathrm{ml} \mathrm{H}_{2} \mathrm{O}, 1.0 \mathrm{ml} 10 \mathrm{~N} \mathrm{NaOH}, 1.0 \mathrm{ml} 0.6$ $\mathrm{N}$ sodium tartrate, $1.0 \mathrm{ml} 2 \%(\mathrm{w} / \mathrm{v})$ gum arabic, and $2.0 \mathrm{ml}$ Nessler's solution (Folin-Wu, Fisher Scientific Co.) were added. The gum arabic and Nessler's solution were filtered through Whatman No. 1 paper before use. The intensity of the resulting brownish-yellow color was measured in a Klett-Summerson colorimeter. Standard nitrogen samples containing glycine were digested and determined with each analysis.

Since this method, like the Kjeldahl procedure, measures primarily reduced $\mathrm{N}$, it is possible that some of the nitrate may not be reduced to ammonia during digestions (Humphries, 1956). Therefore we modified the procedure by adding salicylic acid in the digestion mixture for some samples so that all of the nitrate would be reduced to ammonia (Humphries, 1956). However, this did not increase the ammonia content of the digest, which means that the amount of nitrate was relatively low or it was reduced in the original digestion.

$\mathrm{Ca}, \mathrm{Fe}, \mathrm{K}, \mathrm{Mg}$, and $\mathrm{Mn}$ determination-Ca, $\mathrm{K}, \mathrm{Mg}$, and $\mathrm{Mn}$ levels were determined by neutron activation of dried (undigested) plant material by using short-term irradiation in a pneumatic tube at the Ford Nuclear Reactor in the University of Michigan Phoenix Memorial Lab followed immediately by counting on a GE (LI) gamma ray detector and processing on a Nuclear Data 4420 computer analyzer. In order to measure $\mathrm{Fe}$, the same samples were irradiated in a high flux position $\left(1.5 \times 10^{13}\right.$ neutrons $\left./ \mathrm{cm}^{2}-\mathrm{sec}\right)$ for about $10 \mathrm{hr}$ and then allowed to decay for about 1 week before gamma ray analysis as above. The levels of $\mathrm{Mo}, \mathrm{Zn}, \mathrm{Cu}$ and other minerals which are of interest and which could be determined by this procedure were too low to measure accurately. Owing to the expense of neutron activation, only key samples (leaf blades and seeds) were analyzed and only from selected harvest dates.

$\mathrm{Ca}, \mathrm{K}$, and $\mathrm{Mg}$ concentrations were also determined by atomic absorption spectroscopy on a Jarrell-Ash Atomic Absorption Flame Emission Spectrometer (model 82-526) by using a propane-air mixture. The diluted $\mathrm{H}_{2} \mathrm{SO}_{4}$ digest solutions were used for these determinations, 


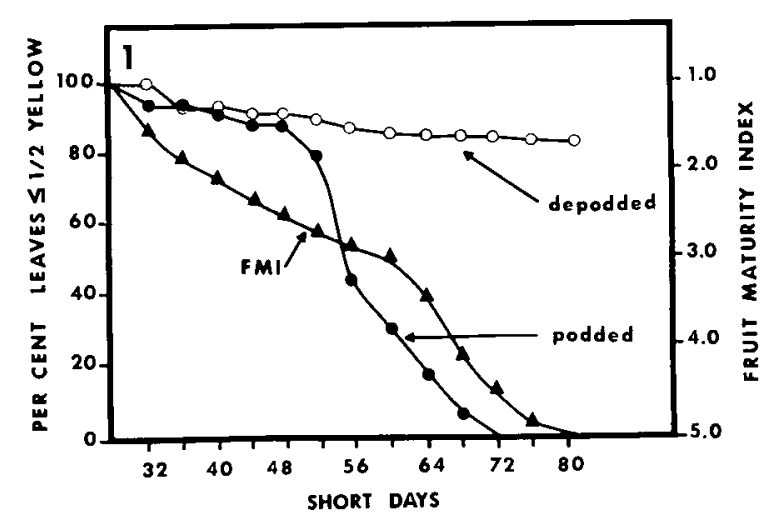

Fig. 1. Time course of senescence and fruit maturation in Anoka soybeans grown in Hoagland's solution.

and ionization was suppressed by adding ultrapure $\mathrm{CsCl}$ (to the $\mathrm{K}$ test solutions) and ultrapure $\mathrm{KCl}$ (to $\mathrm{Ca}$ and $\mathrm{Mg}$ test solutions) to give a final concentration $2 \mathrm{mg} / \mathrm{l} \mathrm{K}$ or Cs.

RESULTS-Senescence and fruit maturationHydroponic plants were used for most of these studies because of the ease of a complete inventory of their parts, e.g., roots and fallen leaves. In addition, the fact that these plants were grown in controlled environment chambers makes them less subject to variations in weather and therefore more uniform than field-grown plants. Because these plants differ somewhat in their appearance, as mentioned above, it seemed important to make determinations on field-grown plants for comparison. The Anoka soybeans grown in Hoagland's solution with a plentiful supply of minerals or in the field showed a time course of fruit maturation and foliar senescence (Fig. 1) qualitatively and quantitatively very similar to the potted plants described elsewhere (Lindoo and Noodén, 1976). In all cases, depodding as or before the fruit reach stage 2 prevented senescence.

Nitrogen-Figure 2A shows the amount of nitrogen in the vegetative parts of hydroponicallygrown plants as the seeds develop. The decrease was particularly striking in the leaf blades, which contained most of the nitrogen until the seeds developed, and there was almost a reciprocal relationship between nitrogen content of the leaf blades and the seeds. Relatively little nitrogen was lost from these plants as a result of the leaf abscission which occurred during this period. The change in leaf nitrogen preceded leaf senescence (cf., Fig. 1 and $2 \mathrm{~A}$ ); in fact, the nitrogen content of the blades had dropped by about $50 \%$ at the time when leaf yellowing started. In addition, both the mg nitrogen per $\mathrm{g}$ fresh weight and per $g$ dry weight of leaves decreased prior to yel- lowing, while the mg nitrogen per g dry weight for seeds increased at first and then decreased (Fig. 2B).

Depodding prevented the drop in nitrogen content of the leaves (Fig. 3A), while it prevented leaf yellowing (Fig. 1), but at the same time, it elevated the nitrogen levels in the stems, carpels and roots. Likewise, depodding blocked the decrease in nitrogen per $g$ fresh weight and dry weight in the leaves (Fig. 3B).

The data obtained for field-grown plants were very similar except that the seeds accumulated twice as much nitrogen as was originally present in the leaf blades. This additional nitrogen probably came from the external environment rather than from the leaves. Since it was not practical to harvest the fallen leaves of field-grown plants, the actual loss of nitrogen in the abscised leaves was not determined.

Curiously, the seeds of both the field-grown plants and those grown hydroponically in environmental control chambers showed a small decrease in nitrogen during the later stages of maturation (19 and 36\%, respectively). At least for the plants grown indoors, this decrease was not the result of seed loss ("pod shattering").

Potassium-The amount of potassium (determined by atomic absorption) in the leaves of hydroponically-grown plants also decreased (Fig. 4A), and this occurred about the same time that yellowing started (Fig. 1); however, most of this loss could be accounted for in the fallen leaves. Nonetheless, seed potassium increased in a manner nearly reciprocal to the levels in the leaves. Compared with nitrogen, a relatively high proportion of the potassium was in the stems, roots, and carpels. Interestingly, the potassium contents of these organs decreased little (stems) or not at all (carpels) or very late (roots). Determination of the potassium content in leaves and seeds of podded plants by neutron activation analysis gave results essentially identical to those from atomic absorption.

In contrast to nitrogen, the potassium content per $g$ fresh weight in the leaves of podded plants did not decrease and even increased during the last stages (Fig. 2B, 4B). The potassium content relative to dry weight also increased in the leaves but remained unchanged in the seeds.

Depodding prevented the changes in potassium levels in the leaves (Fig. 5A, B) and caused a large rise in the amount of potassium in stems.

Podded plants growing in the field underwent similar changes except that the seeds accumulated 2-3 times more potassium than originally present in the leaves.

Magnesium-As the hydroponically-grown, podded plants started to senesce, the amount of 

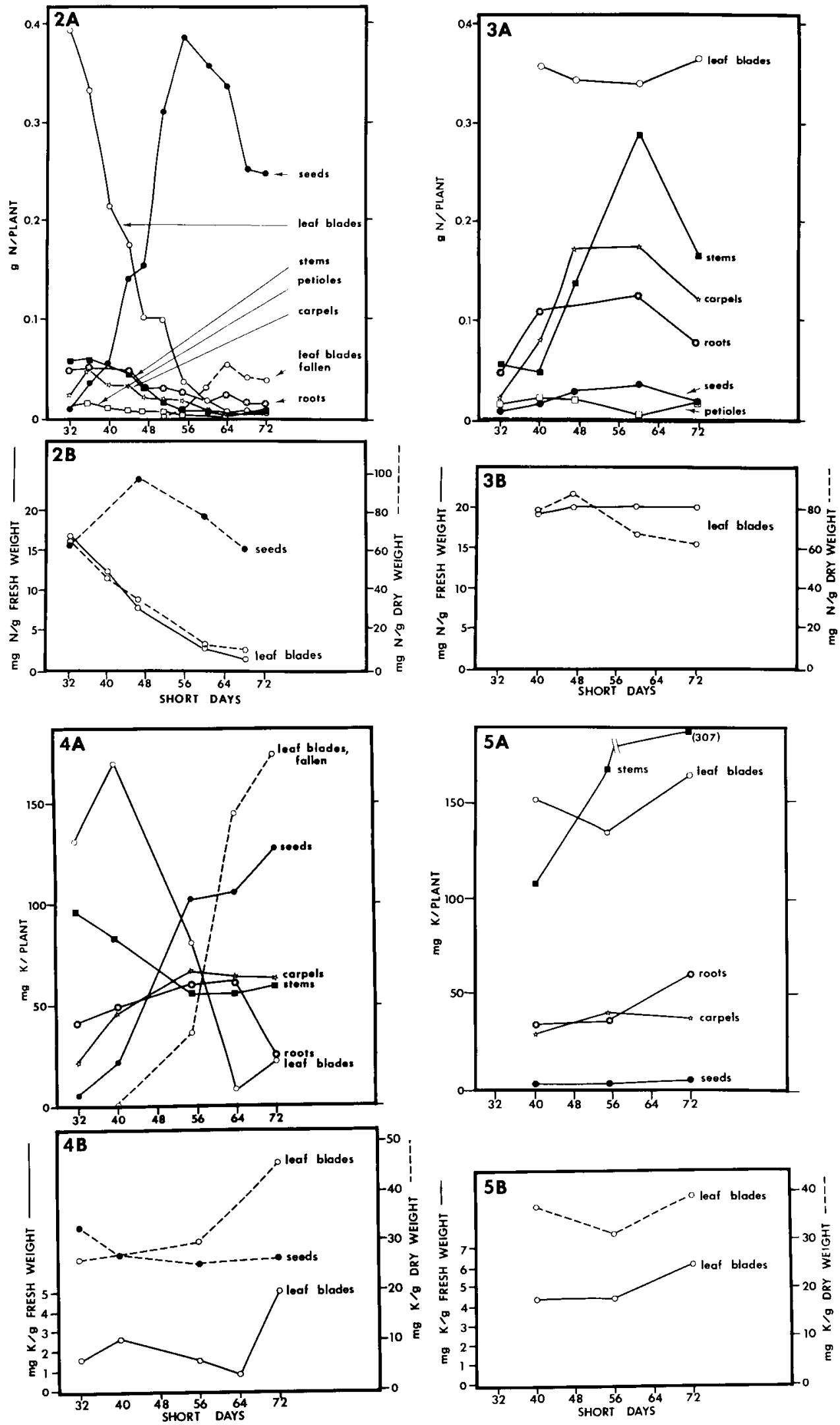
magnesium in the leaf blades decreased markedly (Fig. 6A). Decreases occurred in the stems and possibly in the roots, though to a lesser extent, but the magnesium in the seeds and carpels continued to increase until fairly late into fruit maturation. The gains in the fruit, however, were not quite large enough to account for all the losses. The fallen leaves should account for the rest of the loss, but the amount of magnesium shed with the leaves was small compared with potassium and calcium. The $\mathrm{mg}$ of magnesium per $\mathrm{g}$ fresh weight increased during the later stages of senescence for those leaves which still remained attached to the plant (Fig. 6B). On a dry weight basis, the magnesium content went up in the leaves but stayed about the same in the seeds. Neutron activation analyses showed the same patterns of change in the leaves and seeds of podded plants. Although the samples for the neutron activation and atomic absorption were prepared independently, the values obtained were within $20 \%$ of each other.

Depodding prevented the decrease in magnesium content and even caused large accumulations in the blades, stems and roots (Fig. 7A). Judging from the darker green color of these leaves, an increase in chlorophyll content may account for at least some of the increase in leaf magnesium. As was the case for podded plants, the leaves of depodded plants also increased in magnesium content per $\mathrm{g}$ fresh weight and dry weight (Fig. 7B).

Calcium-The amount of calcium in the leaves and stems of podded, hydroponic plants dropped but increased in the seeds and carpels (Fig. 8A). The loss in the attached leaves clearly exceeded the gain in the seeds, and this loss was accounted for by the fallen leaves. Both the mg calcium per $\mathrm{g}$ fresh weight and dry weight increased, though the latter started earlier (Fig. 8B). By contrast, the calcium content relative to dry weight actually decreased in the seeds. The neutron activation determinations on leaves and seeds of podded plants gave the same patterns, but the amounts of calcium were generally lower (about $40 \%$ less) than the values obtained by atomic absorption. The dramatic decrease in calcium content of the leaves was prevented by depodding (Fig. 9A) as was the increase relative to fresh and dry weight (Fig. 9B).
Field-grown plants showed quantitatively similar changes as the seeds developed.

Iron and manganese-The pattern of changes in iron content of leaves and seeds of podded, hydroponic plants was very similar to that of calcium. The decrease in the blades started about the same time as leaf yellowing and was not equalled by the increase in the seeds (Fig. 10A). During the senescence period, the amount of iron relative to fresh weight of leaves did not change substantially (Fig. 10B). On a dry weight basis, iron decreased in the leaves but increased markedly in the seeds. Some (about $40 \%$ ) of the loss of manganese from leaves was matched by gains in the seeds. On a fresh-weight basis, the manganese content of leaves increased (Fig. 11A, B). The manganese content per $g$ dry weight of leaves rose and then fell late in senescence, while it remained about the same in seeds.

Discussion-Many extensive studies on mineral uptake and distribution during growth and maturation of plants (particularly crop plants) have been published (see Gregory, 1937; Miller, 1938; Williams, 1955; Howell, 1960; Ohlrogge, 1963; Hanway and Weber, 1971; De Mooy et al., 1973; Kollman et al., 1974; Noodén and Leopold, 1978), and some of these have dealt specifically with soybeans (see Howell, 1960; Ohlrogge, 1963; Hanway and Weber, 1971; de Mooy et al., 1973; Kollman et al., 1974). Because these studies have had different objectives, the authors did not attempt to correlate the time course of mineral distribution (or changes in distribution) with senescence. Thus it is difficult (or impossible) to use these earlier results to determine how changes in mineral distribution relate to senescence, e.g., relative starting times or if these processes are parallel. Likewise, data for key organs may be pooled with other parts and inventories are often incomplete (e.g., missing roots). Similarly, the units $(\mathrm{kg} / \mathrm{ha}, \%$ dry weight, $\%$ of total, etc.) employed in many of these studies are of limited use in analyzing changes in mineral contents in relation to senescence. Furthermore, these data are primarily for the minerals of greatest agronomic interest (nitrogen, phosphorus, and potassium). For our purposes, it seemed best to determine the absolute levels of the minerals of interest and to work out inven-

Fig. 2-5. Time course of changes in nitrogen and potassium content during fruit development and senescence in Anoka soybeans grown in Hoagland's solution. Determined by Nesslers reagent (N) or atomic absorption (K). 2. Podded plants. 2A. Total nitrogen in various parts. 2B. Nitrogen content relative to fresh and dry weight. 3. Depodded plants. $3 \mathrm{~A}$. Total nitrogen in various parts. 3B. Nitrogen content relative to fresh and dry weight. 4. Podded plants. 4A. Total potassium in various parts. 4B. Potassium content relative to fresh and dry weight. 5. Depodded plants. 5A. Total potassium in various parts. 5B. Potassium content relative to fresh and dry weight. 

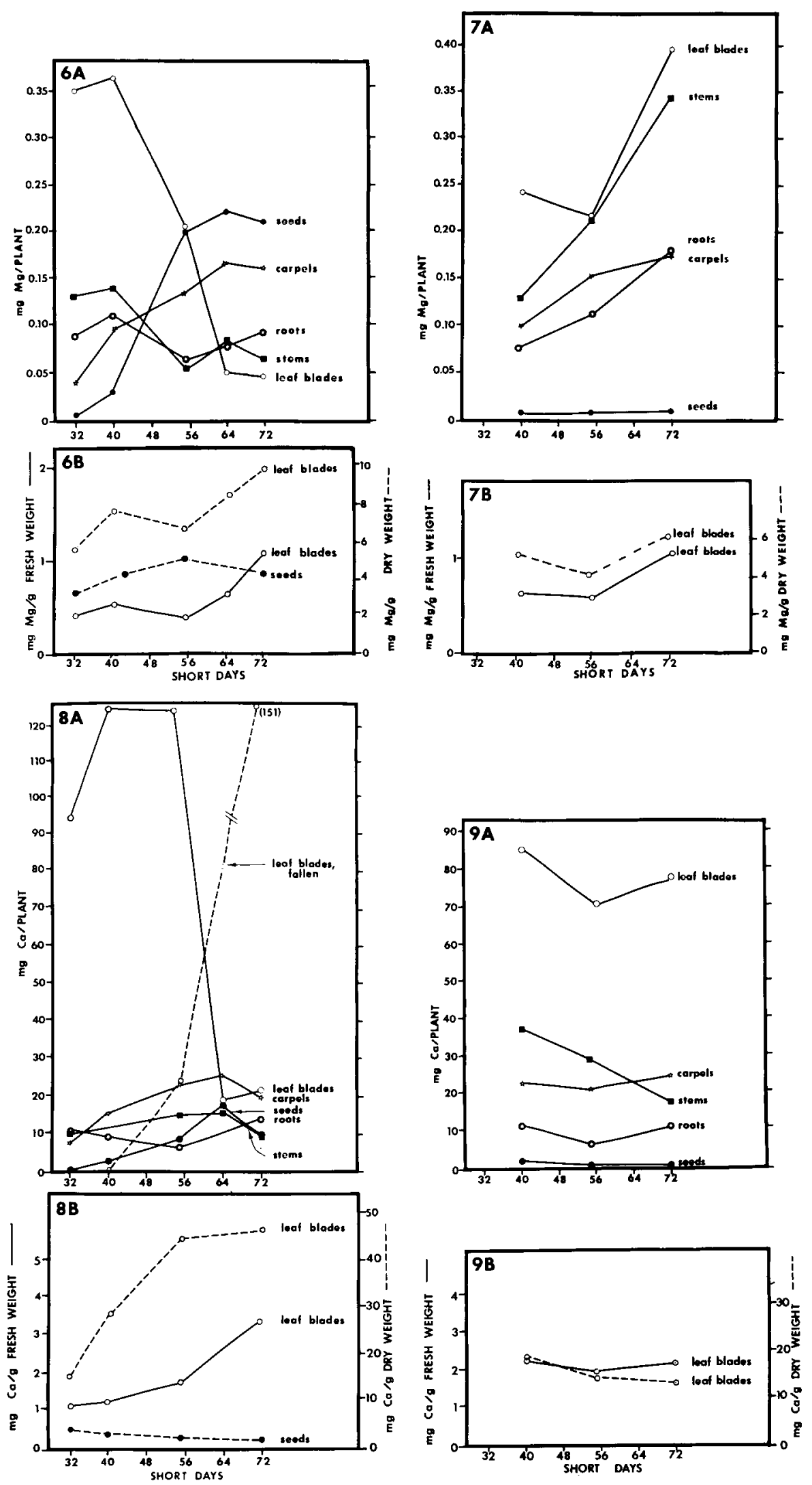
tories for the different plant parts at various stages of leaf senescence and fruit development. In as much as the fresh weight of a leaf does not change greatly during senescence as long as it remains attached to the plant and the plants are well supplied with water, expression of the mineral content relative to fresh weight can show whether or not the concentration changes. This can provide a measure of mineral influx or exodus from the senescing leaves independent of the mineral losses due to shedding of the leaves. Measurements of mineral contents relative to dry weight (or as a percent of dry weight) can be compared as time or development progresses to determine whether or not minerals are accumulated or lost faster than other dry weight components, but it is at this time difficult to interpret these relative changes in relation to senescence. The fact that this measure of mineral content may be altered by either the mineral level or total dry materials, both of which may be changing, limits its usefulness.

The complete inventories for nitrogen, potassium, magnesium and calcium show that the major depot for these minerals in vegetative plants is the leaf blades (also stems in the case of potassium). As the fruits develop, the seeds become major repositories of these minerals (except for calcium), and at least on the surface, this looks like a redistribution from the leaves to the seeds. Two other minerals, manganese and iron, studied less extensively, show losses from the leaves, but the amounts in seeds do not increase correspondingly. Since these leaves start to yellow and abscise at about the time when the amount of these minerals in the leaves declines, one wonders if the decrease is due to (a) redistribution or (b) leaf shedding. The behavior of leaf nitrogen seems different from that of the other minerals studied in that the amount of leaf nitrogen decreases markedly well before leaf yellowing starts and certainly before much abscission occurs. Furthermore, the nitrogen per $g$ fresh weight in leaves drops precipitously, and the amount in fallen leaves is comparatively small. Therefore, nitrogen probably is redistributed from the leaves to the seeds. Studies on nitrogen deficiency symptoms have shown a similar nitrogen mobility with some redistribution from nongrowing to growing regions (Sprague, 1964). Of particular interest is the observation that the $\mathrm{N}$
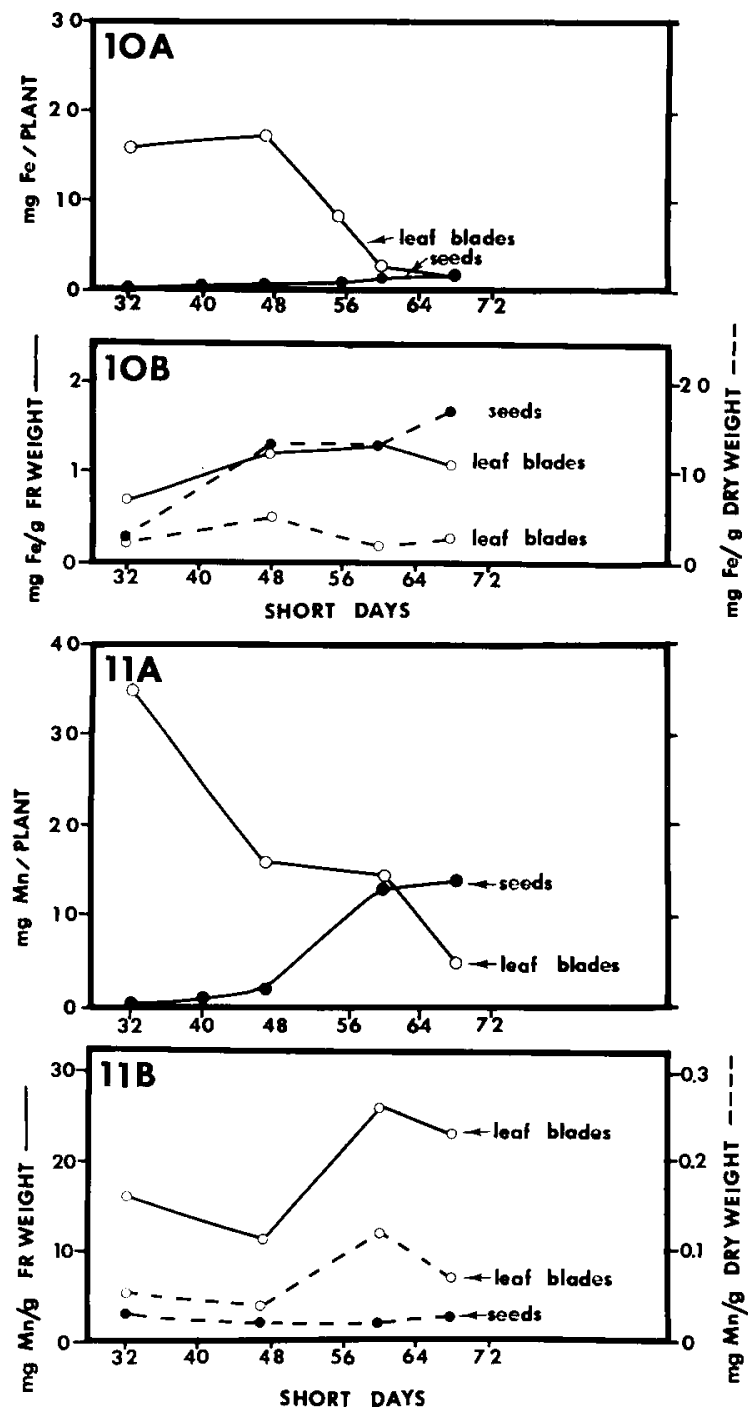

Fig. 10,11. Time course of changes in iron and manganese content during fruit development and senescence in Anoka soybeans grown in Hoagland's solution. Determined by neutron activation. Podded plants. 10A. Total iron in leaf blades and seeds. 10B. Iron content relative to fresh and dry weight. 11A. Total manganese in leaf blades and seeds. 11B. Manganese content relative to fresh and dry weight.

content of leaf blades has decreased to less than $10 \%$ of the original when the chlorosis-inducing effect of the seeds can no longer be prevented by depodding (Lindoo and Noodén, 1977). It is of

Fig. 6-9. Time course of changes in magnesium and calcium content during fruit development and senescence in Anoka soybeans grown in Hoagland's solution. Determined by atomic absorption. 6. Podded plants. 6A. Total magnesium in various parts. 6B. Magnesium content relative to fresh and dry weight. 7. Depodded plants. 7A. Total magnesium in various parts. 7B. Magnesium content relative to fresh and dry weight. 8. Podded plants. 8A. Total calcium in various parts. 8B. Calcium content relative to fresh and dry weight. 9. Depodded plants. 9A. Total calcium in various parts. 9B. Calcium content relative to fresh and dry weight. 
considerable interest that senescence of soybean cotyledons becomes irreversible when a similar proportion, $80 \%$ of their protein, has been lost (Krul, 1974).

Because of a) technical problems (interference in the $\mathrm{H}_{2} \mathrm{SO}_{4}$ digests) and b) the great difference between phosphate deficiency symptoms and the monocarpic senescence syndrome (Sprague, 1964), phosphate distribution was not analyzed here. Earlier reports do, however, contain evidence for some redistribution of phosphate from leaves to fruit and even within flowers during senescence (see Gregory, 1937; Williams, 1955; Howell, 1960; Ohlrogge, 1963; de Mooy et al., 1973; Kollman et al., 1974; Harrison and Arditti, 1976; Noodén and Leopold, 1978).

Since the content of potassium, magnesium, calcium, manganese and iron per $\mathrm{g}$ fresh weight of leaf blades actually increases, or at least fails to decrease, it can be supposed that there is no net efflux of these elements. This suggests that the decline in the foliar potassium and calcium is due to shedding of the leaves, and at least in the cases of potassium and calcium, this has been corroborated by the large amounts in fallen leaves. Thus, it seems likely that potassium, calcium and probably also manganese and iron are not redistributed to any appreciable extent. This is supported by mineral deficiency studies which suggest that calcium, manganese and iron are all immobile elements (Sprague, 1964). Potassium, however, is evidently mobile under mineral deficiency conditions (Sprague, 1964), but the same mobility is not exhibited during monocarpic senescence of our soybeans. In many ways, magnesium looks like another case of immobility, for the level per $g$ fresh weight in leaves does not decrease and actually rises during the last stages of senescence (the last leaves shed from the plant), yet the amounts in fallen leaves are not large enough to account for the losses, which suggests there could be a rapid loss of $\mathrm{Mg}$ just prior to abscission. Therefore, some mineral redistribution probably does occur, but some of the minerals which accumulate in the seeds, particularly potassium, are undoubtedly supplied directly from the roots rather than via the leaves.

The rate of accumulation or loss of a mineral in a particular organ relative to other dry weight components is of interest, even though it is not of paramount importance in considering mineral drain in relation to senescence. Only nitrogen shows a really substantial decrease relative to total dry weight in leaves, while other elements, particularly calcium, increase relative to total dry weight. Obviously, this ratio is determined by a complex balance of processes, yet it supports the idea that leaf nitrogen is relatively mobile. In seeds, only nitrogen and iron seem to accumulate more rapidly than total dry weight, while the other elements studied increase in constant proportion to total dry weight, except for calcium which accumulates less rapidly. What these different patterns of relative loss or accumulation mean to leaf senescence or seed development remains to be determined.

In soybeans, depodding or deflowering can prevent senescence (Leopold et al., 1959; Lindoo and Noodén, 1976; Noodén and Leopold, 1978), and therefore it is of great interest to determine how this treatment affects mineral distribution. The most striking effect of depodding is to prevent the drop in the amounts of minerals in attached leaf blades, and this results from prevention of loss as a result of redistribution or shedding. In addition, depodding alters (prevents) some of the changes in mineral content relative to dry weight. Depodding, however, produces some other changes, most notably an increase in stem potassium and magnesium contents and in prevention of decreases in certain other plant parts. Undoubtedly, depodding has some pronounced effects on mineral distribution, but many are likely to be effects of the prevention of senescence and leaf abscission.

Studies on the effect of reproductive sink size (number of pods allowed to develop) on mineral distribution and uptake in soybeans provide a different perspective and some parallel results (Kollman et al., 1974; McAlister and Krober, 1958). Although there are a number of experimental differences in these studies (in particular, mineral inventories were started at maturity or just before) and senescence was not noted, the data do suggest that depodding (a decreased reproductive sink) may alter the distribution or accumulation of protein, total $\mathrm{N}$ and certain minerals. Depodding appears to prevent the reciprocal change of $\mathrm{N}, \mathrm{P}, \mathrm{Mg}$ and $\mathrm{Ca}$ distribution (the amount of $\mathrm{Ca}$ involved is relatively small) from leaves plus stems to the seeds plus carpels. Our data are in agreement except that we have no determinations for $\mathrm{P}$, and we do not see any net redistribution of $\mathrm{Ca}$. In any case, our data on the changes in concentration of mineral (mineral per $\mathrm{g}$ fresh weight) during senescence show that nitrogen but not potassium, magnesium, calcium, manganese and iron decrease significantly during senescence, and therefore depletion of the latter elements is probably not the cause of leaf senescence during monocarpic senescence of soybeans.

Likewise, spraying the foliage with 0.1 strength Hoagland's solution plus $0.1 \mathrm{M}$ urea (with $0.05 \%, v / v$, Tween 80 ) every 4 days starting during early fruit development (FMI about 1.2) does not delay seed-induced senescence of the leaves, although the treatment does increase seed yield (dry weight) up to $40 \%$, which indicates that at least some of these nutrients pene- 
trate and are utilized (Schreyer-Lindoo and Noodén, 1975). Ramon and Hanway (1976) have likewise reported that minerals applied to the foliage may be utilized to increase seed yield. With the possible exception of nitrogen, which will be considered in a subsequent paper, our results do not support the notion that the developing seeds cause foliar senescence in soybeans by draining or depriving the leaves of needed minerals.

\section{LITERATURE CITED}

ARNon, D. I., AND D. R. Hoagland. 1940. Crop production in artificial solutions and in soils with special reference to factors influencing yields and absorption of inorganic nutrients. Soil Sci. 50: 463-484.

Dawson, R. M., D. C. Elliot, M. H. Elliot, and K. M. JONES. 1969. Data for biochemical research. 2nd ed. Clarendon Press, Oxford.

Gregory, F. G. 1937. Mineral nutrition of plants. Annu. Rev. Biochem. 6: 557-578.

HANWAY, J. J., AND C. R. Weber. 1971. Accumulation of $\mathrm{N}, \mathrm{P}$, and $\mathrm{K}$ by soybean (Glycine max (L.) Merrill) plants. Agron. J. 63: 406-408.

Harrison, C. R., and J. Arditti. 1976. Post-pollination phenomena in orchid flowers. VII. Phosphate movement among floral segments. Amer. J. Bot. 63: 911-918.

Howell, R. W. 1960 . Physiology of the soybean. Adv. Agron. 12: 265-310.

Humphries, E. C. 1956. Mineral components and ash analysis. In I. Paech and M. V. Tracey [eds.], Modern methods of plant analysis, p. 468-502. Vol. I. SpringerVerlag, Berlin.

Kollman, G. E., J. E. Streeter, D. L. Jeffers, and R. B. CURRY. 1974. Accumulation and distribution of mineral nutrients, carbohydrate, and dry matter in soybean plants as influenced by reproductive sink size. Agron. J. 66: 549-554.

KRUL, W. R. 1974. Nucleic acid and protein metabolism of senescing and regenerating soybean cotyledons. Plant Physiol. 54: 36-40.

Leopold, A. C., E. Niedergang-Kamien, And J. Janick. 1959. Experimental modification of plant senescence. Plant Physiol. 34: 570-573.

LINDOO, S. J., AND L. D. NoOdÉN. 1976. The interrelation of fruit development and leaf senescence in "Anoka" soybeans. Bot. Gaz. 137: 218-223.

— AND - 1977. Studies on the behavior of the senescence signal in Anoka soybeans. Plant Physiol. 59: $1136-1140$.

MCAlister, D. F., AND O. A. Krober. 1958. Response of soybeans to leaf and pod removal. Agron. J. 50: 674-677.

Middleton, K. R. 1960. New Nessler reagent and its use in the direct Nesslerization of Kjeldahl digests. J. Appl. Chem. 10: 281-286.

Miller, E. C. 1938. Plant physiology. McGraw-Hill Book Co., Inc., N.Y.

de Mooy, C. J., J. Pesek, and E. Spaldon. 1973. Minera nutrition. In B. E. Caldwell [ed.], Soybeans: Improvement, production, and uses, p. 267-352. Am. Soc. Agron., Inc. Madison.

NoodÉn, L. D., AND A. C. Leopold, 1978. In D. S. Letham, T. J. Higgins, and P. B. Goodwin [eds.], Plant hormones and related compounds. Elsevier Scientific Publishing Co., Amsterdam. (in press.)

Ohlrogge, A. H. 1963. Mineral nutrition of soybeans. In A. G. Norman [ed.], The soybean, p. 125-160. Academic Press, N.Y.

Ramon, G. L., and J. J. Hanway. 1976. Foliar fertilization of soybeans during the seed-filling period. Agron. J. 68: 653-657.

Schreyer-Lindoo, S., AND L. D. NoodÉN. 1975. Screening nutrients and growth promoters or inhibitors for ability to mimic or antagonize the death signal in soybeans. Plant Physiol. 56 (Suppl): 83.

Sprague, H. E. [ed.]. 1964. Hunger signs in crops. 3rd. ed. David McKay Co., N.Y.

WILliams, R. F. 1955. Redistribution of mineral elements during development. Annu. Rev. Plant Physiol. 6: 25-42. 